\title{
Improvement of Post-Thaw Sperm Kinematics and DNA Integrity of Cross-Bred Bovine Sperm by Incorporating DGC as Selection Method Prior to Cryopreservation
}

\author{
Nur Hilwani Ismail ${ }^{1}$, Khairul Osman ${ }^{3}$, Farida Zuraina Mohd Yusof ${ }^{1}$, Syarifah Faezah Syed Mohamad ${ }^{1}$, \\ Farah Hanan Fatihah Jaafar ${ }^{2}$ \& Siti Fatimah Ibrahim² \\ ${ }^{1}$ School of Biological Sciences, Faculty of Applied Sciences, Universiti Teknologi MARA, Selangor, Malaysia \\ ${ }^{2}$ Department of Physiology, Universiti Kebangsaan Malaysia Medical Center, Kuala Lumpur, Malaysia \\ ${ }^{3}$ Centre of Diagnostic Science and Applied Health, Faculty of Health Sciences, Universiti Kebangsaan Malaysia, \\ Selangor, Malaysia \\ Correspondence: Nur Hilwani Ismail, School of Biological Sciences, Faculty of Applied Sciences, Universiti \\ Teknologi MARA, Shah Alam 40450, Selangor, Malaysia. Tel: 60-355-438-435. E-mail: \\ hilwani@salam.uitm.edu.my
}

Received: October 3, 2017

Accepted: December 13, 2017

Online Published: December 31, 2017

doi:10.5539/jas.v9n13p24

URL: https://doi.org/10.5539/jas.v9n13p24

The research is financed by the Excellence Fund of Universiti Teknologi MARA (600-RMI/ST/DANA 5/3/Dst (263/2009) and Research University Fund of Universiti Kebangsaan Malaysia (FF-162-2009).

\begin{abstract}
The aim of this study was to assess post-thaw sperm quality following initial sperm selection using density gradient centrifugation (DGC) prior to cryopreservation. Ejaculates from four mature Charolais cross Kedah-Kelantan bulls were collected using artificial vagina at IBVK Pahang, Malaysia. The ejaculates were aliquoted into 3 groups: non-cryopreserved group (NC); control group of cryopreserved sperm without DGC (ND) and treatment group of sperm undergoing DGC sperm selection before cryopreservation (CDGC). Prior to analysis, samples from both cryopreserved groups were thawed at $37^{\circ} \mathrm{C}$ for $30 \mathrm{sec}$. All samples were analysed for kinematics parameters, viability and compromise in DNA integrity (evaluated as DNA Fragmentation Index, DFI). All kinematics parameters were analysed using computer aided sperm analysis (CASA). Results indicated significant $(\mathrm{p}<0.05)$ kinematics parameter changes for all parameters of velocity $(\mathrm{VCL}, \mathrm{VSL}, \mathrm{VAP})$ and progression (WOB, LIN, ALH and BCF). Unfortunately, changes in spermatozoa straightness were insignificant (STR) $\mathrm{F}(2,68)=1.004, \mathrm{p}=0.371$. Spermatozoa viability had increased by $26.2 \%(\mathrm{p}<0.01)$ following the treatment. DFI revealed the treatment group recorded a significant reduction in DFI value $(0.17 \%$ fragmented DNA). In conclusion, DGC sperm selection prior to cryopreservation reduced the effects of cryodamage and showed an improvement in post-thaw sperm quality, thus reducing the occurrence of asthenozoospermia in populations of frozen-thawed cross-bred bovine spermatozoa.
\end{abstract}

Keywords: bull sperm, cryopreservation, DNA integrity, sperm kinematics, density gradient centrifugation (DGC)

\section{Introduction}

Previous accounts of shortened lifespan in frozen-thawed sperm samples have been reported across many species (Cerolini et al., 2001; Katila, 2001; O'Connell et al., 2002; Breininger et al., 2005; Knox et al., 2015; Mari et al., 2015 ) and have affected the outcome of breeding programs utilising these samples.

The induced cryodamage following cryopreservative procedures have known to render sperm immotile with increased DNA fragmentation index (DFI). Findings suggest that compromise in the quality of cryopreserved sperm is likely due to synergistic effect of environmental and cyrobiological factors (Bailey et al., 2000). Previous studies have established that using sperm from heterogeneous populations for cryopreservation would later result in deteriorated post-thaw values for sperm kinematics and viability (Verstegen et al., 2002; Murase et al., 2010). Cooper et al. (2010) defined high quality sperm as those exhibiting morphological and kinematic 
values above the minimal baseline values as suggested by the World Health Organization guidelines (Wakayama et al., 1998). The use of substandard sperm would affect the fertilizing efficacy of the sperm and thus overall artificial insemination success rate (Szczygiel et al., 2002). In order to obtain a homogenous population from post-thaw sperm samples, it is advisable for a sperm selection method to be included as part of the cryopreservation routine. Several methods of selection are available such as swim-up procedure, migration-sedimentation technique, glass wool filtration and density gradient centrifugation (DGC).

Swim-up procedure is a favourable technique used to obtain good quality sperm. However, a limited number of motile sperm are collected due to the inability of sperm in the compacted pellet in penetrating the interface layer of the cell culture in the swim-up procedure. Therefore showing a marked reduction in the yield of motile sperm (Muiño et al., 2008). It has been postulated that the pellet may contain good quality sperm that are unable to swim up due to various obstruction in the pellet. Furthermore, due to the sperm being in close proximity to cell debris and leukocytes, apoptosis would likely occur earlier than expected. Very likely, the cell debris and leukocytes would have produced high levels of reactive oxygen species (ROS) thus increasing lipid peroxidation (du Plessis et al., 2008).

On the other hand, migration-sedimentation technique produces very clean fractions of motile sperm with reduced levels of ROS. Since this method includes minimum use of mechanical separation, it has been classified as a relatively gentle method of separation (Sakkas et al., 2000). However, there are constraints in the effectiveness of this method, as a high sperm count and a sperm population of at least moderate motility is required. This is challenging as yields are sometimes of low motility. Cost of carrying out an analysis is expensive as it requires special glass or plastic tubes. These factors have made the method impractical commercially.

Glass wool filtration is an easy method to perform, with moderate yields of sperm with average motility functions. Level of ROS is usually significantly reduced with an ability to eliminate $90 \%$ of lymphocytes (Henkel \& Schill, 2003). Therefore, sperm with low sperm density could be used for separation. Nonetheless, the fundamental process underlying the separation technique very much depends on the chemistry, surface structure and charge of the glass wool. This renders the technique expensive to implement and resulting filtrate from separation possess remnants of glass wool and high degree of debris.

DGC on the other hand, propagates clean fractions with leukocytes removed; reduced ROS levels and yields are of optimal quality. Since density gradient centrifugation has a promising future, development into improving this method further is undergoing. Previous research focused on replacing the Percoll ${ }^{\circledR}$ component with that of ISolate ${ }^{\circledR}$ (Claassens et al., 1998). The modification was implemented as reports that Percoll ${ }^{\circledR}$ has endotoxin properties which would impact the health of human patient and offspring (Henkel \& Schill, 2003). DGC has proven higher efficacy comparable to other conventional techniques and therefore has been continuously implemented and favoured as a method of separation (Henkel \& Schill, 2003).

As mentioned, the development of density gradient has been centred on its usefulness in human infertility. No in depth study had ever been conducted around its ability to improve fertility in endangered animal species, animals for large-scale feed lotting or dairy. Thus this study intends to ascertain the feasibility of DGC cell sorting prior to cryopreservation in improving the occurrences of asthenozoospermia in populations of frozen-thawed cross-bred bovine sperm.

\section{Method}

\subsection{Maintenance of Animal and Sample Collection}

Bulls were maintained at the Institute Bioteknologi Veterinar Kebangsaan (IBVK) Pahang, Malaysia as free ranging bulls raised in isolation of other males or females. The diet consisted of grass and pellets supplemented with $10 \%$ elemental selenium. Semen was collected with an artificial vagina from four mature bulls (36-48 months old) of Charolais x Kedah-Kelantan breed with average collection of 3 ejaculates per bull and an average of $10 \mathrm{~mL}$ per ejaculate. Sampling was conducted in the morning of every 3 days to allow the bulls to rest between sampling. Each bull was allowed to mount a teaser bull and the sperm rich fraction was collected using an artificial vagina (AV). Study protocol was approved by the institution's animal ethical committee (PP/FISIO/2010/FATIMAH/20-May/305-June-2010-June-2012).

\subsection{Sample Processing and DGC Selection Process Prior to Cryopreservation}

Volume and concentration of ejaculates were determined using SpermaCue ${ }^{\mathrm{TM}}$, Minitüb Germany. Settings of analysis parameters for motility using Animal Breeder software (CEROS, Hamilton Thorne, Inc., Beverly, MA, USA) were based on values suggested by Farrel et al. (1998) and Bradshaw et al. (2006). Ejaculates were 
separated into 3 groups (i) NC: fresh untreated samples; (ii) ND: cryopreserved sperm without DGC and (iii) CDGC: treatment group with the use of DGC for sperm separation preceding cryopreservation.

DGC sperm separation was achieved through exposing the sperm to density separation with ISolate ${ }^{\circledR}$, Irvine Scientific, Santa Ana, California. The isolation of suitable sperm using DGC was conducted in accordance with manufacturer's protocol. Following separation, the supernatant containing cellular debris and non-viable sperm was removed, and the resulting pellet was resuspended in Bioxcell ${ }^{\circledR}$ (IMV, L'Aigle, France) preceding cryopreservation.

\subsection{Cryopreservation of Sperm Samples}

Cryogenic suitability of sample was determined by selecting ejaculates with baseline values of minimum $70 \%$ motile and $60 \%$ viable sperm. Cryopreservation of sperm was conducted according to method by Faezah et al. (2014). The cryopreserved straws were thawed in water baths at $37^{\circ} \mathrm{C}$ for $30 \mathrm{sec}$ for subsequent analysis. Both groups of spermatozoa were cryopreserved following this protocol.

\subsection{Sperm Viability Analysis}

The control and treatment groups were analysed for viability using Eosin-Nigrosin (EN) staining technique (Joint, 2005). Slides were observed under $40 \times$ magnification, bright field microscope and the number of viable sperm cells (non-stained cells) and non-viable sperm cells (cells stained pink to purple) were tallied respectively. A minimum of 200 sperm cells were analysed per data entry per treatment group with a replication of ten slides per analysis.

\subsection{Sperm Kinematics Analysis}

Measurements of sperm kinematics were divided into sperm velocity and progression. Measurements for velocity were based on (i) average path velocity, VAP $(\mu \mathrm{m} / \mathrm{s})$, (ii) progressive velocity, VSL ( $\mu \mathrm{m} / \mathrm{s})$ and (iii) track speed, VCL $(\mu \mathrm{m} / \mathrm{s})$ values. Meanwhile, progression was based on (i) straightness, STR (VSL/VAP, \%), (ii) linearity, LIN (VSL/VCL, \%) and (iii) wobble, WOB (VAP/VCL, \%). Additional sperm values evaluated were ALH (amplitude of lateral head displacement, $\mu \mathrm{m}$ ) and BCF (beat cross frequency, Hz). All analyses were conducted in triplicates using 300 straws of cryopreserved sperm with frame rate acquisition set at $60 \mathrm{~Hz}$ using the Computer Aided Sperm Analyzer (CASA).

\subsection{Analysis of DNA integrity}

DNA integrity assay was conducted using the SPERM-HALOMAX® kit for Bos taurus sperm (Halotech DNA SL, Spain). All procedures were conducted according to manufacturer's instructions. Following the series of processing using SPERM-HALOMAX ${ }^{\circledR}$, the slide was left to air dry prior to being stained with $10 \mu 1$ of DNA specific fluorochrome. The slides were observed immediately under fluorescent microscopy at $40 \times$ magnification. Sperm cells with fragmented DNA exhibit an expanded halo around the head of the sperm cell, which is characteristic of chromatin DNA dispersion. A total of 300 sperm cells per data entry were observed and enumerated for DNA Fragmentation Index (DFI) with a minimum of ten slides per analysis. Sperm DNA with conserved integrity will have lower DFI values as compared to damaged DNA.

\subsection{Statistical Analysis}

Descriptive statistics and Analysis of Variance (ANOVA) with post hoc tests at significance level of $\mathrm{p}<0.05$ was conducted on motility and progression data. The percentage of viable sperm was calculated using student T-Test (NC against ND; and NC against CDGC). Data for DNA integrity was recorded by enumerating sperm with fragmented DNA and analysis was conducted using Mann-Whitney U test. Data were considered significant at $\mathrm{p}$ $<0.05$.

\section{Results}

Average volume of collected ejaculates was $4.32 \pm 0.37 \mathrm{~mL}$ per ejaculate. On the other hand, concentration of neat sperm collected valued $218.94 \times 10^{7} \pm 36.65 \times 10^{7} \mathrm{sperm} / \mathrm{mL}$. This was adjusted to $20 \times 10^{6} \pm 5 \times 10^{6}$ sperm $/ \mathrm{mL}$ by the addition of extenders prior to cryopreservation. All sperm concentration utilized for following analyses fell within the acceptable range of the parameter. The percentage of retrieved motile sperm cells after cryopreservation remained constant with the inclusion of DGC. This was proven from motility analysis using CASA that showed significant increase in overall motility rates, motility patterns, and viability rates following cryopreservation (Table 1). Motility percentage after cryopreservation in CDGC and ND groups recorded values of $50.1 \pm 2.63 \%$ and $49.9 \pm 2.7 \%$ respectively $(\mathrm{F}(2,107)=0.585, \mathrm{p}=0.559)$. The values for progressive motility indicated a prominent increase from $77.63 \pm 10.43 \%$ as compared to $93.67 \pm 6.06 \%$ after separation $(\mathrm{F}(2,107)=$ 
$0.585, \mathrm{p}=0.559)$. The overall progressive motility percentage following treatment with DGC in CDGC group recorded no significant improvement.

Nonetheless, DGC had significantly increased the percentage of retrieved viable sperm after cryopreservation. This was evident by the $26.2 \%(\mathrm{p}<0.01)$ increase in retrieved viable sperm (Figure 1) following the supra-vital staining method of Eosin-Nigrosin staining technique. DGC had substantially increased the percentage of viable sperm yield. Viable spermatozoa collected within the pellet of spermatozoa exhibiting no morphological anomalies. The statistical values for velocity (VCL $(\mu \mathrm{m} / \mathrm{s})$, VSL $(\mu \mathrm{m} / \mathrm{s})$, and VAP $(\mu \mathrm{m} / \mathrm{s})$ ), progression (STR $(\%)$, LIN (\%), WOB (\%), ALH $(\mu \mathrm{m})$ and BCF $(\mathrm{Hz}))$ parameters are shown in Table 1. The multiple comparisons test showed that the velocity of sperm after DGC fractionation in CDGC group improved for VAP and VSL but a significant decline was evident for VCL values $(p<0.05)$. LIN, WOB and beat cross frequency $(\mathrm{BCF})$ of the flagellar movement parameters also decreased significantly. However, ALH $(\mu \mathrm{m})$ values increased. Measure of straightness (STR (\%)) remained unchanged following treatment. Table 1 reports the percentages of retrieved motile sperm cells after cryopreservation without DGC (ND group) and with DGC treatment (CDGC group) recorded values of $49.9 \pm 2.7 \%$ and $50.1 \pm 2.63 \%$ respectively $(\mathrm{F}(2,107)=0.585, \mathrm{p}=0.559)$. The values for progressive motility indicated a prominent increase from $77.63 \pm 10.43 \%$ as compared to $93.67 \pm 6.06 \%$ after separation $(\mathrm{F}(2,107)=0.585, \mathrm{p}=0.559)$.

Table 1. Statistical descriptors of bull sperm kinematic parameters of different sperm groups $(\mathrm{n}>200)^{\mathrm{h}}$

\begin{tabular}{|c|c|c|c|}
\hline \multirow{2}{*}{ Kinetic Parameters } & \multicolumn{3}{|c|}{ Sperm Groups $($ mean \pm SEM $) \dagger$} \\
\hline & NC & ND & CDGC \\
\hline \multicolumn{4}{|l|}{ Velocity Parameters } \\
\hline $\mathrm{VAP}, \mu \mathrm{m} / \mathrm{s}$ & $125.18 \pm 4.00$ & $97.33 \pm 3.81^{\mathrm{a}}$ & $118.39 \pm 2.63^{\mathrm{a}}$ \\
\hline $\mathrm{VSL}, \mu \mathrm{m} / \mathrm{s}$ & $108.59 \pm 3.04$ & $89.10 \pm 3.54^{\mathrm{b}}$ & $106.34 \pm 2.45^{b}$ \\
\hline $\mathrm{VCL}, \mu \mathrm{m} / \mathrm{s}$ & $176.43 \pm 6.50$ & $124.85 \pm 6.08^{c}$ & $104.99 \pm 5.60^{\mathrm{c}}$ \\
\hline \multicolumn{4}{|l|}{ Progression Parameters } \\
\hline LIN, \% & $64.74 \pm 1.41$ & $74.71 \pm 1.66^{\mathrm{d}}$ & $68.87 \pm 0.68^{\mathrm{d}}$ \\
\hline STR, \% & $87.22 \pm 0.87$ & $90.29 \pm 1.64$ & $90.00 \pm 0.56$ \\
\hline WOB, \% & $71.51 \pm 0.95$ & $80.36 \pm 1.27^{\mathrm{e}}$ & $74.21 \pm 0.51^{\mathrm{e}}$ \\
\hline ALH & $6.31 \pm 0.29$ & $4.03 \pm 0.19^{\mathrm{f}}$ & $5.34 \pm 0.13^{\mathrm{f}}$ \\
\hline $\mathrm{BCF}, \mathrm{Hz}$ & $10.94 \pm 1.08$ & $16.38 \pm 0.73^{\mathrm{g}}$ & $10.73 \pm 0.85^{\mathrm{g}}$ \\
\hline Motility, \% & $54.26 \pm 3.49$ & $49.90 \pm 2.70$ & $50.10 \pm 2.63$ \\
\hline Progressive Motility, \% & $100^{*}$ & $77.63 \pm 10.43$ & $93.67 \pm 6.06$ \\
\hline
\end{tabular}

Note. $\dagger \mathrm{NC}=$ fresh semen; $\mathrm{ND}=$ post-cryopreservation without DGC treatment; $\mathrm{CDGC}=$ post-cryopreservation with DGC treatment.

* The value of Progressive Motility for Group NC (consisted of untreated sperm from fresh ejaculate) was read after $3 \mathrm{hr}$ temperature equilibrium at $4{ }^{\circ} \mathrm{C}$. This step was carried on the cells from group $\mathrm{NC}$ as it is compulsory in standard cryopreservative procedures to avoid the formation of ice crystals in the cells by controlling the drop in temperature before submerging the cells in liquid nitrogen.

abcdefg Identical letters in the same row indicate significant values.

${ }^{\mathrm{h}}$ The study was conducted in triplicates.

VAP, average path velocity; VSL, progressive velocity; VCL, track speed; STR, straightness; LIN, linearity; WOB, wobble; ALH, amplitude of lateral head displacement and BCF, beat cross frequency.

Nonetheless, DGC had significantly increased the percentage of retrieved viable sperm after cryopreservation. This was evident by the $26.2 \%$ increase $(p<0.01)$ in retrieved viable sperm following the supra-vital staining method of Eosin-Nigrosin staining technique (Figure 1). 


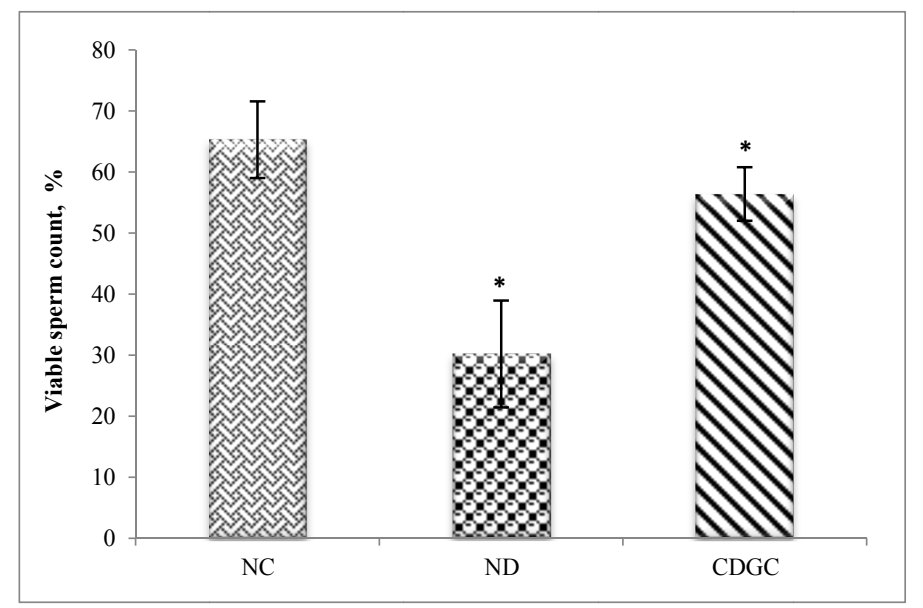

Figure 1. Assessment of viable sperm yield between untreated fresh sperm (NC) with post-thaw cryopreserved untreated sperm (ND) and post-thaw cryopreserved DGC treated sperm (CDGC)

Note. * Statistical analysis was considered significant at $\mathrm{p}<0.05$ between all groups.

A Mann-Whitney U test (Table 2) was used to evaluate the hypothesis that control sub-population of sperm would score a higher percentage of DNA fragmentation than treated sub-population of sperm in a DNA fragmentation analysis. The results were significant, with a $\mathrm{z}$ score of $-4.048, \mathrm{p}<0.05$.

Table 2. Results of Mann-Whitney U test for the analysis of DNA Fragmentation in control and treatment sub-population of sperm using SPERM-Halomax ${ }^{\circledR}$

\begin{tabular}{|c|c|c|c|}
\hline & \multicolumn{2}{|c|}{ Sperm sub-population } & \multirow{2}{*}{ p value } \\
\hline & Control & Treatment & \\
\hline DNA Fragmentation Index, \% & $1.52 \pm 0.22$ & $0.17 \pm 0.58$ & \multirow{2}{*}{$<0.01$} \\
\hline Mean Rank & 24.07 & 9.75 & \\
\hline
\end{tabular}

\section{Discussion}

Lateral head movement, ALH and LIN are two factors, which are strongly related to spermatozoa fertilizing capacity (Aitken \& West, 1990; Irvine, 1995; Bedaiwy et al., 2003; Aitken, 2017). Meanwhile, ALH and BCF are indicators for sperm swimming motion (Verstegen et al., 2002). LIN, STR and WOB are factors governing the linear trajectory of sperm motion whereas VCL, VSL, and VAP are criterions of sperm activity (Cardona Maya et al., 2007; El-Ruby et al., 2017). It is inferred that these parameters are significant during zona pellucida penetration. The observed velocity and progression parameters in ND and CDGC groups could be the result of disrupted plasma membrane equilibrium that ensued in compromised viability. This was reported to be prevalent in cryopreserved sperm and has been identified as cryo-induced damage and compromises the functionality of sperm surviving the thawing procedure following cryopreservation (Cremades et al., 2005). An elaborate description of cryo-induced damage was put forth by Bailey et al. (2000) and described it as damage to the plasma membrane especially to the main body of the sperm, the midpiece, and distinct damage to the head.

In addition, membrane permeability and selective permeability to calcium was likely compromised, rendering a permanent damage to the sperm's osmolarity regulation. According to Gravance et al. (1998) this observation can be explained after further inspection on the ultra-structure of the sperm following cryopreservation. Reorganization of the lipids at the extracellular structure in turn affects the fluidity of the membrane; reduced sperm head size and eventually changes sperm kinetics (Bailey et al., 2000).

Data from sperm motility showed distinct characterisation of activated sperm movements after the treatment of DGC. Increase in VSL values limits the effects of reduced STR and LIN values and produces flagellar beating, which was more symmetrical (Bolanca et al., 2016). This leads to the inference that the treatment group comprised of activated sperm, which are preferred over hyperactivated sperm. 
Hyperactivated sperm exhibit qualities of compromised motility and progression characterised by vigorous, non-linear, non-progressive motility where all values of VSL, STR and LIN are reduced (McGEE \& Herr, 1987). This leads to asymmetrical flagella beating. Hyperactivated sperm are closely associated with capacitation and acrosomal reaction taking place in the female reproductive tracts (Farrell et al., 1998). However, the increase in VSL values and reduction in STR and LIN values in CDGC group as compared to ND group showed that the resulting sperm population from the study comprised of activated sperm, did not undergo capacitation and were suitable for use in artificial insemination as its motility and progression were enhanced, congruent with studies by Singh et al. (2017) and Goodson et al. (2017).

Results of the DNA fragmentation analysis revealed that $1.52 \%$ of the control sub-population exhibited fragmentation. The treatment group, scored nine times less the amount of the control group with only $0.17 \%$ DNA fragmentation present (Table 2). These findings are corroborated by studies conducted by Yildiz et al. (2007) and WHO (2010) which reported the correlations between the presence of nuclear DNA alterations in mature sperm and impaired reproductive efficiency in animals.

The values of kinematic parameters in CDGC group (Table 1), is concurrent with previous findings (WHO, 2010). Overall, the decrease in all velocity parameters (VAP, VSL and VCL) and progression parameters (increase in LIN, STR and WOB; decrease in ALH and constant for BCF value) is characteristic of enhanced performance on sperm kinetics. This data is most significant as it validates the findings on DNA fragmentation in the CDGC group, which was substantially lower than the NC group (Table 2). It also further proves that kinematic performance can be conserved if not enhanced with the presence of intact DNA. In conclusion, the outcomes of the kinetic parameters for post-thaw cryopreserved spermatozoa show that the values improved with DGC separation system and have increased the occurrence of sperm with intact DNA by reducing the values obtained from DFI analysis. This further validates that spermatozoa from the CDGC group sustained minimal damage to their DNA following separation and cryopreservation and is suitable for implementation in various artificial insemination procedures (Joint FAO, 2005; Fraser, 2017; Parthipan et al., 2017). By having sperm with high DNA integrity, the sperm conserved its repair mechanism and was able to reduce the detrimental effects of cryodamage. However, the fertility potential of the CDGC sperm population has yet to be determined and confirmed through further research.

\section{Acknowledgements}

This research was financed by the Excellence Fund of Universiti Teknologi MARA (600-RMI/ST/DANA 5/3/Dst (263/2009) and Research University Fund of Universiti Kebangsaan Malaysia (FF-162-2009) under the purview of Ministry of Education Malaysia. N.H.I. wrote the manuscript, conducted the experiments and analysed the data. K.O. contributed to the main conceptual ideas and facilitated with analysis of data. F.Z.M.Y. and S.F.I. contributed the design and implementation of the research. S.F.S.Y. and F.H.F.J. contributed with the sampling for the study. All authors discussed the results and contributed to the final manuscript. Authors would like to thank Prof. Dr. Noorzan Mohd Noor (Professor of linguistics) for proof reading the manuscript and Institute Bioteknologi Veterinar Kebangsaan (IBVK), Malaysia for assistance in semen sampling and technical advice. Authors would like to acknowledge Research Management Centre, Universiti Teknologi MARA, Malaysia and the Faculty of Applied Sciences, Universiti Teknologi MARA, Malaysia for their support.

\section{References}

Aitken, R. J. (2017). DNA damage in human spermatozoa: Important contributor to mutagenesis in the offspring. Translational Andrology and Urology, 6(Suppl. 4), S761. https://doi.org/10.21037/tau.2017.09.13

Aitken, R., \& West, K. (1990). Analysis of the relationship between reactive oxygen species production and leucocyte infiltration in fractions of human semen separated on Percoll gradients. International Journal of Andrology, 13, 433-451. https://doi.org/10.1111/j.1365-2605.1990.tb01051.x

Bailey, J. L., Bilodeau, J., \& Cormier, N. (2000). Semen cryopreservation in domestic animals: A damaging and capacitating phenomenon. Journal of Andrology, 21, 1-7. https://doi.org/10.1002/j.1939-4640.2000. tb03268.x

Bedaiwy, M. A., Sharma, R. K., Alhussaini, T. K., Mohamed, M. S., Aleem, A. M. A., Nelson. D. R., ... Agarwal, A. (2003). The use of novel semen quality scores to predict pregnancy in couples with male-factor infertility undergoing intrauterine insemination. Journal of Andrology, 24, 353-360. https://doi.org/10.1002/ j.1939-4640.2003.tb02682.x 
Bolanca, I., Obhodas, J., Ljiljak, D., Matjacic, L., \& Kuna, K. (2016). Synergetic Effects of K, Ca, Cu and Zn in Human Semen in Relation to Parameters Indicative of Spontaneous Hyperactivation of Spermatozoa. PloS One, 11(3), e0152445. https://doi.org/10.1371/journal.pone.0152445

Bradshaw, C. J. A., Isagi, Y., Kaneko, S., Bowman, D. M. J. S., \& Brook, B. W. (2006). Conservation Value of Non-Native Banteng in Northern Australia. Conservation Biology, 20, 1306-1311. https://doi.org/10.1111/ j.1523-1739.2006.00428.x

Breininger, E., Beorlegui, N. B., O’Flaherty, C. M., \& Beconi, M. T. (2005). Alpha-tocopherol improves biochemical and dynamic parameters in cryopreserved boar semen. Theriogenology, 63, 2126-2135. https://doi.org/10.1016/j.theriogenology.2004.08.016

Cardona Maya, W. D., Gutiérrez, J. A. B., De los Rios, J., \& Caramillo, A. (2007). Functional evaluation of sperm in Colombian fertile men. Archivos Españoles de Urología, 60(7), 827-831. https://doi.org/10.4321/ S0004-06142007000700019

Cerolini, S., Maldjian, A., Pizzi, F., \& Gliozzi, T. (2001). Changes in sperm quality and lipid composition during cryopreservation of boar semen. Reproduction, 121, 395-401. https://doi.org/10.1530/rep.0.1210395

Claassens, O., Menkveld, R., \& Harrison, K. (1998). Evaluation of three substitutes for Percoll in sperm isolation by density gradient centrifugation. Human Reproduction, 13, 3139. https://doi.org/10.1093/humrep/ 13.11.3139

Cooper, T. G., Noonan, E., Von Eckardstein, S., Auger, J., Baker, H., Behre, H. M., ... Mbizvo, M. T. (2010). World Health Organization reference values for human semen characteristics. Human Reproduction Update, 16, 231. https://doi.org/10.1093/humupd/dmp048

Cremades, T., Roca, J., Rodriguez-Martinez, H., Abaigar, T., Vazquez, J. M., \& Martinez, E. A. (2005). Kinematic changes during the cryopreservation of boar spermatozoa. Journal of Andrology, $26,610$. https://doi.org/10.2164/jandrol.05028

du Plessis, S. S., Makker, K., Desai, N. R., \& Agarwal, A. (2008). Impact of oxidative stress on IVF. Expert Revision Obstetrics Gynecology, 3, 539-554. https://doi.org/10.1586/17474108.3.4.539

El-Ruby, A. M., Bedier, M. S. H. W., Montaser, A. M., Badr, M. R., Hegab, A. O., \& Zaabel, S. M. (2017). Improvement of in vitro fertilization in buffalo by increasing the fertilizing capacity of spermatozoa. Alexandria Journal of Veterinary Sciences, 53(2), 6-10. https://doi.org//10.5455/ajvs.264914

Faezah, S., Zuraina, F., Farah, J., Khairul, O., Hilwani, N., Iswadi, M., ... Fatimah, S. (2014). The effects of magnetic separation on cryopreserved bovine spermatozoa motility, viability and cryo-capacitation status. Zygote, 22, 378-386. https://doi.org/10.1017/S0967199412000597

Farrell, P., Presicce, G., Brockett, C., \& Foote, R. (1998). Quantification of bull sperm characteristics measured by computer-assisted sperm analysis (CASA) and the relationship to fertility. Theriogenology, 49, 871-879. https://doi.org/10.1016/S0093-691X(98)00036-3

Fraser, L. (2017). Markers for Sperm Freezability and Relevance of Transcriptome Studies in Semen Cryopreservation: A Review. Theriogenology. InTech. https://doi.org//10.5772/intechopen.68651

Goodson, S. G., White, S., Stevans, A. M., Bhat, S., Kao, C. Y., Jaworski, S., ... O’Brien, D. A. (2017). CASAnova: A multiclass support vector machine model for the classification of human sperm motility patterns. Biology of Reproduction, 97(5), 698-708. https://doi.org/10.1093/biolre/iox120

Gravance, C., Vishwanath, R., Pitt, C., Garner, D., \& Casey, P. (1998). Effects of cryopreservation on bull sperm head morphometry. Journal of Andrology, 19, 704. https://doi.org/10.1002/j.1939-4640.1998.tb02079.x

Henkel, R. R., \& Schill, W. B. (2003). Sperm preparation for ART. Reproduction Biology and Endocrinology, 1, 108. https://doi.org/10.1186/1477-7827-1-108

Irvine, D. S. (1995). Computer assisted semen analysis systems: Sperm motility assessment. Human Reproduction, 10, 53-59. https://doi.org/10.1093/humrep/10.suppl_1.53

Joint, F. A. O. (2005). Improving artificial breeding of cattle and buffalo in Asia. Guidelines and recommendations. A manual prepared under the framework of an IAEA Technical Cooperation Regional RCA Project on 'Improving Animal Productivity and Reproductive Efficiency', with technical support of the Joint FAO/IAEA Division of Nuclear Techniques in Food and Agriculture (No. IAEA-TECDOC-1480). Joint FAO/IAEA Division of Nuclear Techniques in Food and Agriculture, Vienna, Austria. Retrieved from http:/www-pub.iaea.org/MTCD/publications/PDF/TE_1480_web.pdf 
Katila, T. (2001). In vitro evaluation of frozen-thawed stallion semen: A review. Acta Veterinaria Scandinavica, 42, 199-218. https://doi.org/10.1186/1751-0147-42-199

Knox, R., Ringwelski, J., McNamara, K., Aardsma, M., \& Bojko, M. (2015). The effect of extender, method of thawing, and duration of storage on in vitro fertility measures of frozen-thawed boar sperm. Theriogenology, 84(3), 407-412. https://doi.org/10.1016/j.theriogenology.2015.03.029

Mari, G., Bucci, D., Love, C., Mislei, B., Rizzato, G., Giaretta, E., Merlo, B., \& Spinaci, M. (2015). Effect of cushioned or single layer semen centrifugation before sex sorting on frozen stallion semen quality. Theriogenology, 83, 953-958. https://doi.org/10.1016/j.theriogenology.2014.11.031

McGEE, R. S., \& Herr, J. C. (1987). Human seminal vesicle-specific antigen during semen liquefaction. Biology Reproduction, 37, 431-439. https://doi.org/10.1095/biolreprod37.2.431

Muiño, R., Rivera, M., Rigau, T., Rodriguez-Gil, J., \& Peña, A. (2008). Effect of different thawing rates on post-thaw sperm viability, kinematic parameters and motile sperm subpopulations structure of bull semen. Animal Reproduction Science, 109, 50-64. https://doi.org/10.1016/j.anireprosci.2007.11.028

Murase, T., El-Kon, I., Harayama, H., Mukoujima, K., Takasu, M., \& Sakai, K. (2010). Hyperactivated Motility of Frozen-Thawed Spermatozoa from Fertile and Subfertile Japanese Black Bulls Induced by Cyclic Adenosine 3',5'-Monophosphate Analogue, cBiMPS. Journal Reproduction Develop, 56, 36-40. https://doi.org/10.1262/jrd.09-082N

O’connell, M., McClure, N., \& Lewis, S. (2002). The effects of cryopreservation on sperm morphology, motility and mitochondrial function. Human Reproduction, 17, 704-709. https://doi.org/10.1093/humrep/17.3.704

Parthipan, S., Selvaraju, S., Somashekar, L., Arangasamy, A., Sivaram, M., \& Ravindra, J. P. (2017). Spermatozoal transcripts expression levels are predictive of semen quality and conception rate in bulls (Bos taurus). Theriogenology, 98, 41-49. https://doi.org/10.1016/j.theriogenology.2017.04.042

Sakkas, D., Manicardi, G., Tomlinson, M., Mandrioli, M., Bizzaro, D., Bianchi, P., \& Bianchi, U. (2000). The use of two density gradient centrifugation techniques and the swim-up method to separate spermatozoa with chromatin and nuclear DNA anomalies. Human Reproduction, 15, 1112. https://doi.org/10.1093/humrep/ 15.5.1112

Singh, R. K., Kumaresan, A., Mir, M. A., Kumar, P., Chhillar, S., Tripathi, U. K., ... Mohanty, T. K. (2017). Computer assisted sperm analysis: Relationship between the movement characteristics of buffalo spermatozoa and sire fertility. Indian J. Anim. Res., 51(4), 660-664. https://doi.org/10.18805/ijar.10768

Szczygiel, M. A., Kusakabe, H., Yanagimachi, R., \& Whittingham, D. G. (2002). Separation of motile populations of spermatozoa prior to freezing is beneficial for subsequent fertilization in vitro: A study with various mouse strains. Biology Reproduction, 67, 287-292. https://doi.org/10.1095/biolreprod67.1.287

Verstegen, J., Iguer-Ouada, M., \& Onclin, K. (2002). Computer assisted semen analyzers in andrology research and veterinary practice. Theriogenology, 57, 149-179. https://doi.org/10.1016/S0093-691X(01)00664-1

Wakayama, T., Whittingham, D., \& Yanagimachi, R. (1998). Production of normal offspring from mouse oocytes injected with spermatozoa cryopreserved with or without cryoprotection. Journal Reproduction Fertility, 112, 11-17. https://doi.org/10.1530/jrf.0.1120011

WHO (World Health Organization). (2010). WHO laboratory manual for the examination and processing of human semen (5th ed.).

Yildiz, C., Ottaviani, P., Law, N., Ayearst, R., Liu, L., \& McKerlie, C. (2007). Effects of cryopreservation on sperm quality, nuclear DNA integrity, in vitro fertilization, and in vitro embryo development in the mouse. Reproduction, 133, 585. https://doi.org/10.1530/REP-06-0256

\section{Copyrights}

Copyright for this article is retained by the author(s), with first publication rights granted to the journal.

This is an open-access article distributed under the terms and conditions of the Creative Commons Attribution license (http://creativecommons.org/licenses/by/4.0/). 